УДК 551.58(571.56)

ЧИСЛЕННОЕ МОДЕЛИРОВАНИЕ КЛИМАТА ЦЕНТРАЛЬНОЙ ЯКУТИИ

${ }^{1}$ Поморцев О.А., ${ }^{2}$ Поморцева А.А.

${ }^{\prime}$ ФГАОУ ВО «Северо-Восточный федеральный университет им. М.К. Аммосова», Якутск, e-mail: olegpomortsev@mail.ru;

${ }^{2}$ ФГБОУ ВО «Санкт-Петербургский горный университет, Санкт-Петербург, e-mail: a.a.pomortseva@mail.ru

Рассматривается проблема изменений климата Центральной Якутии и влияния климата на природные процессы в криолитозоне. Представлены новые данные о связи изменений климата с фактором солнечной активности (СА), модулирующим режим глобальной циркуляции атмосферы и Сибирского антициклона. В масштабах векового цикла СА XX в. исследован отклик среднегодовой температуры станции Якутск на режим СА. Приводятся данные о влиянии на развитие современной волны потепления в Якутии перехода зональной циркуляции атмосферы к энергетически более эффективному меридиональному типу. Методами численного моделирования временных рядов наблюдений метеостанции Якутск (более чем за столетие) впервые построена модель изменчивости тепло- и влагообеспеченности климата. Выявлено запаздывание хода атмосферных осадков относительно температуры на 1/4 ритмической волны. Установлена последовательная смена климатических фаз: холодно-сухой (ХС), тепло-сухой (ХВ), холодно-влажной (XB) и тепло-влажной (ТВ). Показана высокая степень влияния солнечной активности на климат и нелинейность солнечно-тропосферных связей на уровне внутривековых и вековых осцилляций. Определены хронологические координаты опасных аномалий климата и отклика вечной мерзлоты на ближайшие десятилетия и столетие в целом. Согласно выявленным гелиогеофизическим предпосылкам, сильные засухи следует ожидать в первой половине - середине 2020-х гг. (2021-2025), а также в 2040-е и начале 2070-х гг. Они будут чередоваться либо совпадать (на отдельных участках) с сезонами, отличающимися ливневым характером атмосферных осадков. Эти явления будет модулировать периодичность широкомасштабных лесных пожаров и усиление динамики всего спектра опасных криогенных экзогенных геологических процессов. Во временных диапазонах, близких к переломным моментам (минимумам и максимумам) 11-летнего цикла, следует ожидать усиление рисков гидрологических, гидрогеологических, криогенных и сейсмо-тектонических проявлений.

Ключевые слова: солнечная активность, солнечный цикл, математическая модель, прогноз, среднегодовая температура, атмосферные осадки, числа Вольфа

\title{
NUMERICAL MODELING THE CLIMATE CENTRAL YAKUTIA
}

\section{${ }^{1}$ Pomortsev O.A., ${ }^{2}$ Pomortseva A.A.}

${ }^{1}$ North-Eastern Federal University named after M.K. Ammosov, Yakutsk, e-mail: olegpomortsev@mail.ru; ${ }^{2}$ Saint Petersburg Mining University, Saint Petersburg, e-mail: a.a.pomortseva@mail.ru

The problem of climate changes in Central Yakutia and the influence of climate on natural processes in the cryolithic zone is considered. We present new data on the relationship between climate change and the solar activity factor (SA) modulating the mode of global circulation of the atmsphere and the Siberian anticyclone. The response of the mean annual temperature of Yakutsk station to the SA regime was investigated on the scale of the century cycle of SA of the twentieth century. Data on the effect on the development of the modern wave of warming in Yakutia of the transition of zonal circulation of the atmosphere to a more energy-efficient meridional type are presented. Numerical simulations of time series of observations of Yakutsk weather station (more than a century) for the first time built a model of variability of heat and moisture availability of the climate during the century cycle of SA. The lag of the course of atmospheric precipitation relative to temperature for $1 / 4$ of the rhythmic wave was revealed. Consecutive change of climatic phases: cold-dry (CD), warm-dry (WD), coldhumid $(\mathrm{CH})$ and warm-humid $(\mathrm{WH})$ has been established. A high degree of influence of solar activity on climate and nonlinearity of solar-tropospheric relations at the level of intra- and secular oscillations are shown. The chronological coordinates of dangerous climate anomalies and permafrost response for the next decades and the century as a whole were determined. According to the identified heliogeophysical preconditions, strong droughts should be expected in the first half to the middle of the 2020s (2021-2025) and in the 2040s and early 2070s. They will alternate, or coincide (in some areas) with seasons characterized by heavy precipitation. These phenomena will modulate the periodicity of large-scale forest fires and the intensification of the dynamics of the entire spectrum of dangerous cryogenic exogenic geological processes. In time ranges close to turning points (minimums and maximums) of the 11-year cycle, we should expect increased risks of hydrological, hydrogeological, cryogenic and seismo-tectonic manifestations.

Keywords: solar activity, solar cycle, mathematical model, forecast, annual mean temperature, atmospheric precipitation, Wolf numbers

Проблема изменений климата, несмотря на современные углубленные и всесторонние исследования, все еще носит дискус- сионный характер [1]. В качестве главной причины потепления называют как антропогенные, так и природные факторы. До- 
минирует газовая концепция потепления, в основе которой лежит теория эмиссии парниковых газов антропогенного генезиса. Но климат - глобальный процесс, связанный прежде всего с положением Земли в Солнечной системе и влиянием периодической (циклической) ритмики Солнца. Об этом свидетельствуют фундаментальные исследования А.В. Дьякова [2], М.С. Эйгенсона [3] и Б.А. Слепцова-Шевлевича [4] и др. Климатические прогнозы А.В. Дьякова (на 3-6 месяцев вперёд) для любой точки Северного полушария отличались поразительной точностью. Они строились на энерго-климатологической основе и оправдывались на 80-90\% [2]. Все это вызывает интерес к проблеме солнечно-тропосферных связей, а моделирование долговременных рядов метеорологических наблюдений занимает в этом случае ключевое место.

\section{Постановка задачи}

В качестве исходных приняты ряды метеорологических наблюдений за среднегодовой температурой приземного воздуха и атмосферными осадками на ГМС Якутск (Центральная Якутия). Они берут начало с мая 1829 г. (рис. 1) [5]. Однако наличие значительных перерывов в 1850-1870х гг. ограничило начало непрерывного ряда 1882 г. (138 лет).

Выбор метеостанции Якутск не случаен. Он обусловлен не только максимальной для Восточной Сибири продолжительностью ряда наблюдений, но и географическим положением. Станция расположена на Центрально-Якутской равнине, обрамленной с востока и юга цепями горных хребтов, блокирующими вторжения воздушных масс с акватории Тихого океана. Она также значи- тельно удалена от теплых воздушных масс Атлантики и имеет хороший отклик на изменение солнечной активности (СА) [5, 3]. Наши исследования Сибирского антициклона и современного потепления показали, что ряды наблюдений ГМС Якутск являются высокорепрезентативными не только для большей части Среднесибирского плоскогорья, но и для всего Северного полушария [5].

В качестве показателя СА использовался Цюрихский ряд чисел Вольфа продолжительностью более 300 лет.

Цель работы - методами численного моделирования нестационариных процессов в рядах метеорологии ГМС Якутск (среднегодовые температуры и атмосферные осадки) и чисел Вольфа исследовать солнечно-тропосферные связи на уровне внутривековых и вековых осцилляций в приложении к обоснованию долгосрочного географического прогноза.

Задачи:

- уточнить тенденции изменений климата и солнечной активности за последнее столетие путем вычисления линейных трендов в рядах метеонаблюдений и чисел Вольфа;

- методом скользящих средних выполнить моделирование кривых тепло- и влагообеспеченности климата по ходу векового цикла солнечной активности;

- исследовать закономерности флуктуаций климата под влиянием фактора глобальной цируляции атмосферы и гармонических осцилляций СА;

- определить наиболее вероятные изменения и грядущие аномалии климата в приложение к долгосрочному географическому прогнозу и прежде всего климатическому и мерзлотному.

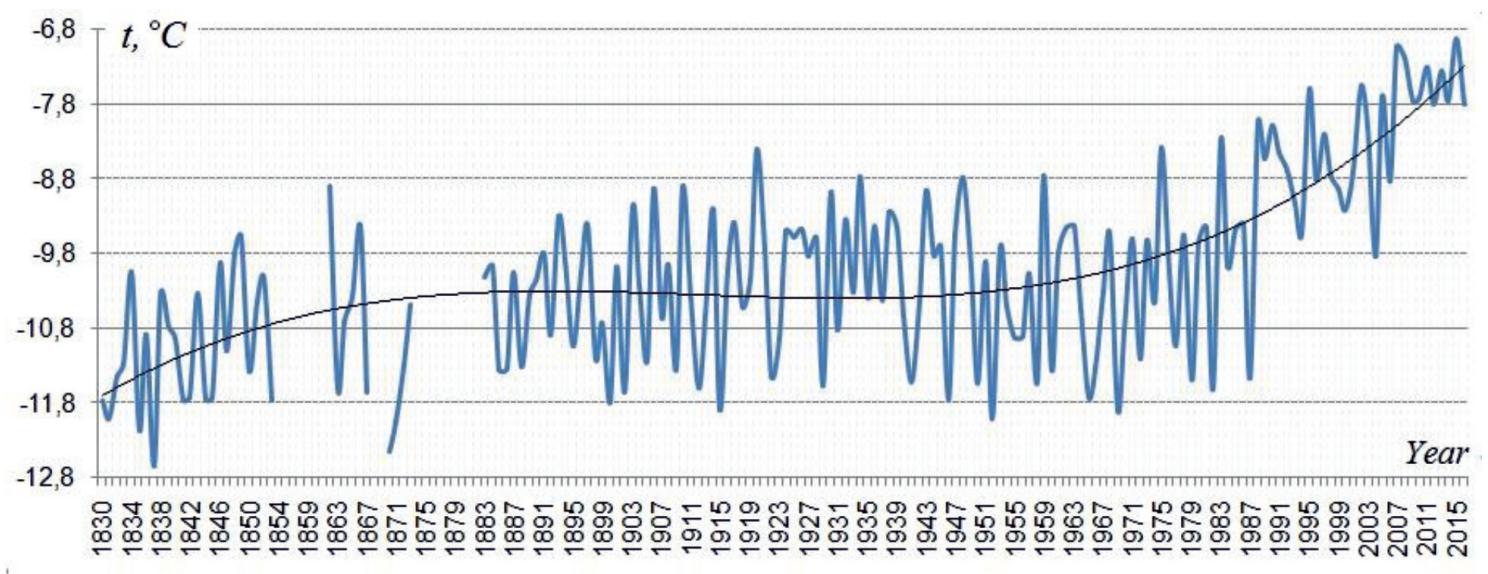

Рис. 1. График средней температуры в Якутске с 1830 по 2016 г. [5] 


\section{Результаты исследования и их обсуждение}

Вычисление линейных трендов в рядах температуры и атмосферных осадков станции Якутск в графическом сопоставлении с линейным трендом чисел Вольфа за XX в. показало, что прирост температуры лишь ненамного отставал от положительных трендов атмосферных осадков и чисел Вольфа, имеющих близкие показатели за рассматриваемый период (рис. 2 и 3 ).

Это свидетельствует о единых тенденциях в активности Солнца и динамике тропосферно-климатических процессов. Солнечная активность, как было показано М.С. Эйгенсоном [3], способна модулировать не только колебания климата на уровне гармоник 11-летнего цикла СА, но и более продолжительные - на долговременной основе. Совпадения линейных трендов температуры, атмосферных осадков и чисел Вольфа в наших моделях подтверждают выводы М.С. Эйгенсона и могут свидетель- ствовать в пользу влияния СА на глобальный климат, в том числе и на процесс развития современного потепления. Этот вывод подтверждается и результатами других исследований [6-8]. Моделирование рядов метеорологических элементов методами Фурье и вейвлет-анализа показало присутствие в их структуре осцилляций, близких к известным периодичностям солнечной ритмики: 11-летней (Швабе - Вольфа), 22-летней (Хэла), 35-40-летней (Брикнера) и др. $[9,10]$. Однако прямое графическое сопоставление кривых Фурье исследуемых рядов и кривой чисел Вольфа показало, что отклик гармоник анализа Фурье в рядах метеорологических элементов на 11-летние осцилляции СА был неоднозначен. В одних случаях положительные аномалии температуры и атмосферного увлажнения совпадали с максимумами 11-летних циклов $\mathrm{CA}$, в других - с минимумами, либо занимали промежуточное положение, тяготея то к ветви подъема, то к ветви спада 11-летнего цикла (рис. 4 и 5).

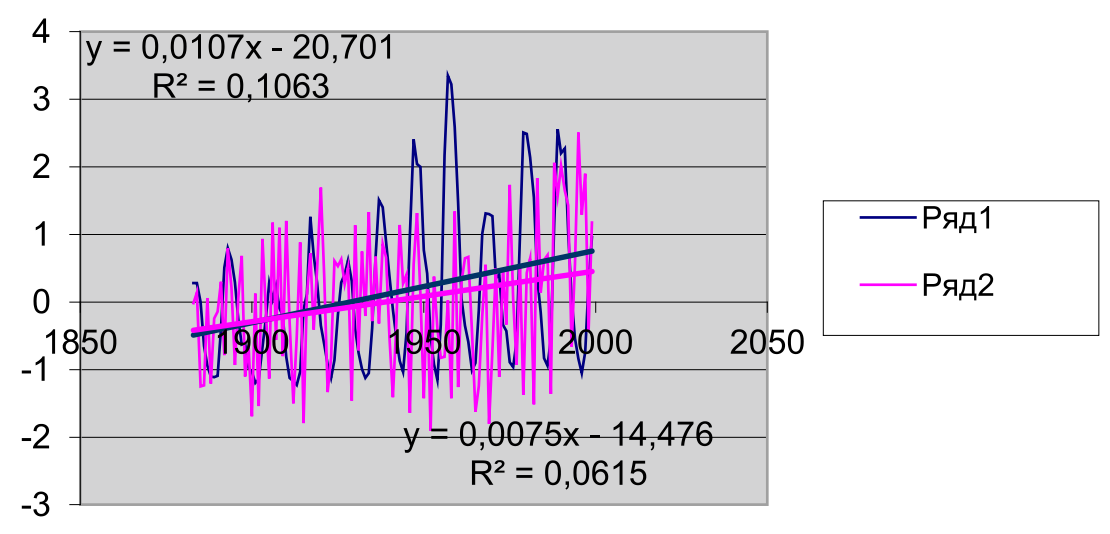

Рис. 2. Линейные тренды значений чисел Вольфа (1) и среднегодовой температуры по станциии Якутск (2)

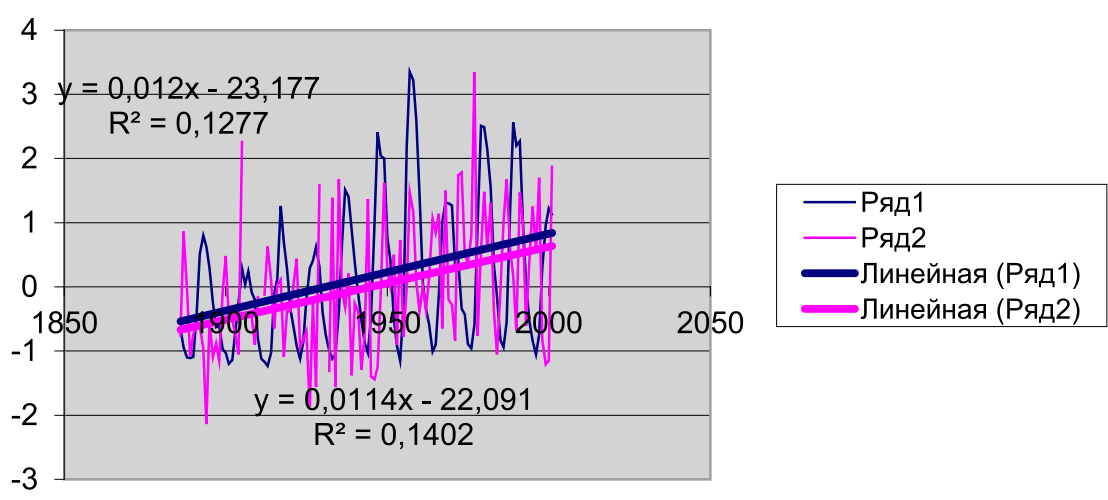

Рис. 3. Линейнье тренды значений чисел Вольфа (1) и среднегодовых атмосферных осадков по станичии Якутск (2) 


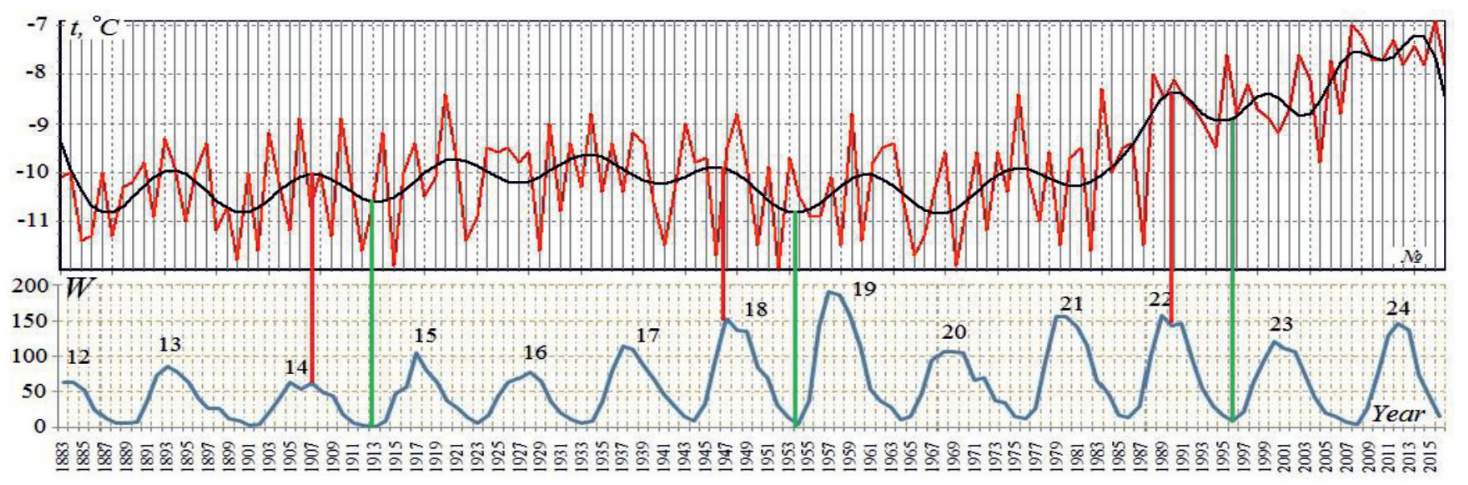

Рис. 4. Диаграммы значений среднегодовой температуры воздуха натурального ряда $\left({ }^{\circ} \mathrm{C}\right)$ и анализа Фурье по данным ГМС Якутск и солнечной активности (W)

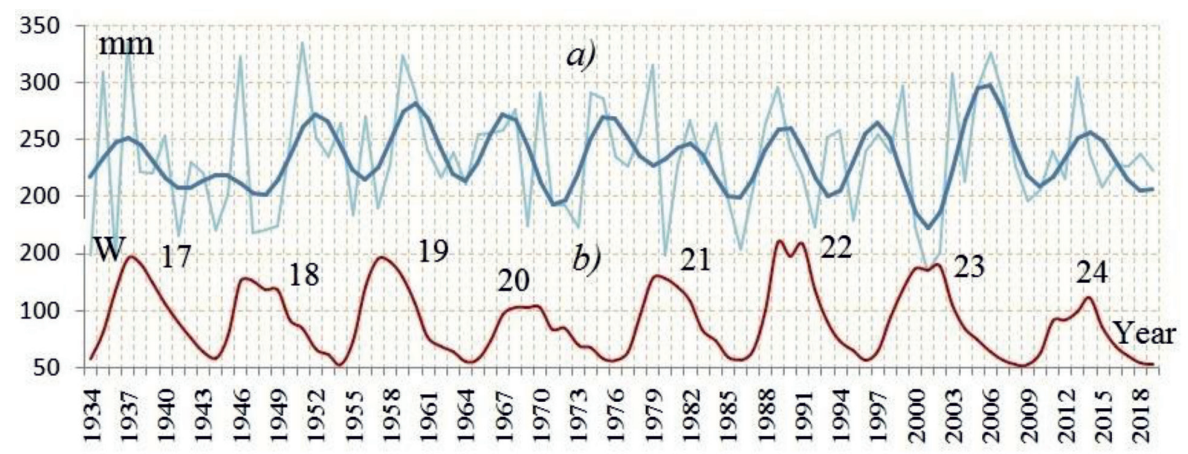

Рис. 5. Диаграмма значений среднегодовых атмосферных осадков натурального ряда (мм) и Фурье анализа по данным ГМС Якутск и солнечной активности (W)

Очевиден нелинейный характер солнечно-тропосферных связей. Он проявляется в устойчивом запаздывании по фазе гармонических осцилляций в рядах метеорологических элементов относительно аномалий 11-летнегоцикла(максимумов иминимумов): на $1 / 4$ периода температуры и на $1 / 2$ - атмосферных осадков. Этой закономерности подчинен весь спектр ритмики, вскрытой нами в метеорологических рядах ГМС Якутск. На это указывают результаты как наших, так и других исследований [11-13].

В целом полученные результаты раскрывают большое влияние солнечных ритмов на динамику среднегодовой температуры и режим атмосферных осадков. Запаздывание по фазе отклика аномалий метеорологических элементов на аномалии СА могут свидетельствовать в пользу инерционности в отклике атмосферы на внешние энергетические воздействия, связанные с периодической деятельностью Солнца.

Как известно, при оценке климата любого региона Земли важную роль играет сочетание тепла и влаги. Поэтому ис- следования по поиску закономерностей в многолетней изменчивости тепло- и влагообеспеченности климата представляются актуальными. Путем математического моделирования метеорологических рядов ГМС Якутск (среднегодовые температуры и атмосферные осадки) была построена модель тепловлагообеспеченности климата (рис. 6). Модель показала чередование в XX в. четырех климатических интервалов: холодного и сухого (ХC); теплого и сухого (ТС); холодного и влажного (ХB); теплого и влажного (ТВ). При этом была выявлена очень важная закономерность ходы кривой температуры опережали ходы кривой атмосферных осадков на $1 / 4$ каждой внутривековой ритмической волны. Ранее подобное запаздывание кривой увлажненности относительно теплообеспеченности было открыто Е.В. Максимовым при палеогеографических реконструкциях долгопериодичных - тысячелетних и многотысячелетних климатических циклов. Это явление было названо им правилом Иверсена - Гричук [14]. 


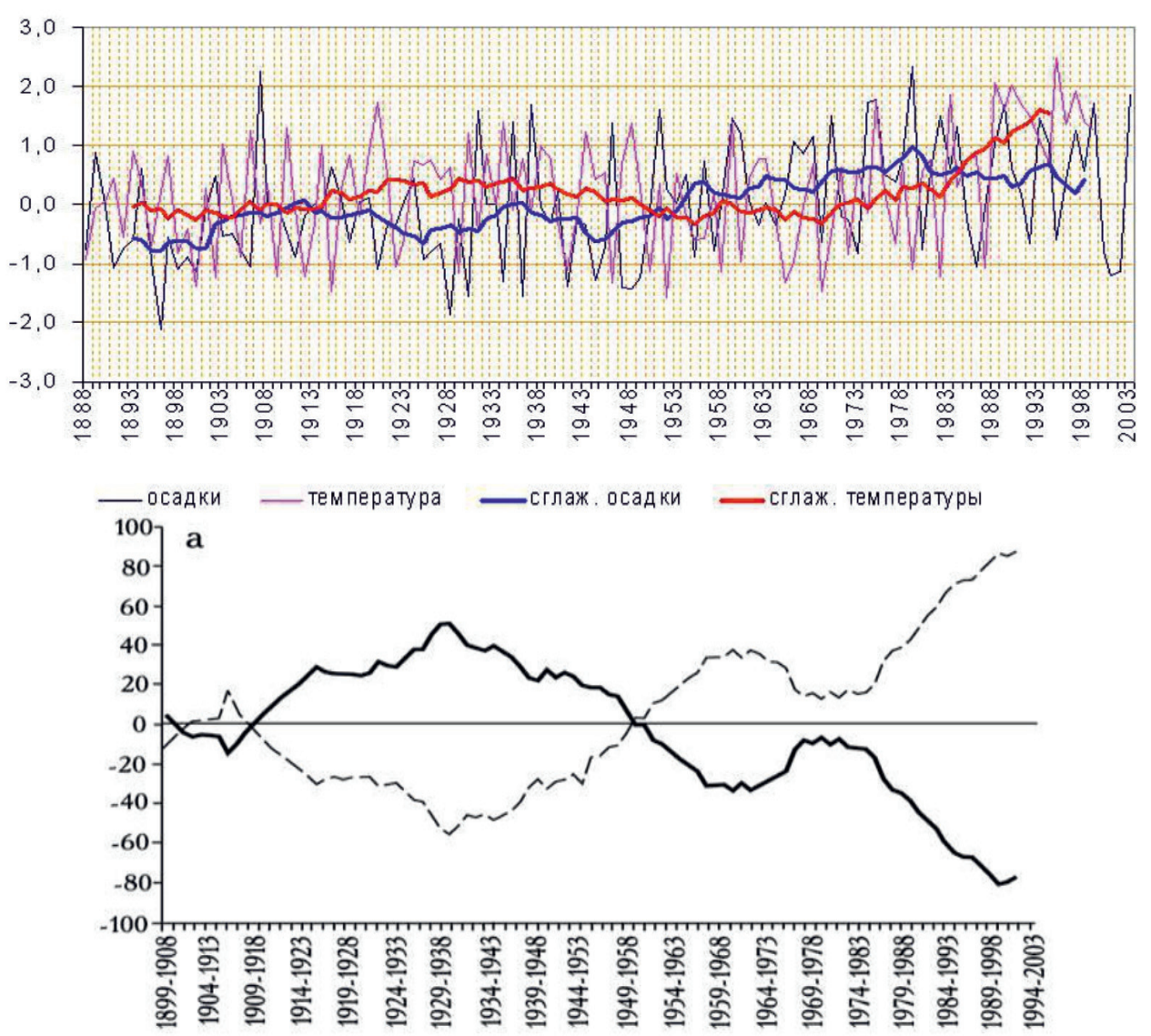

Рис. 6. Диаграмма среднегодовой температуры приземного воздуха и атмосферных осадков (11-летние скользящче) по данным метеостанщии Якутск и атмосферная цүиркулящия (сплошная линия - зональная, пунктирная-меридиональная) (а)

Представляется, что в основе этого явления, в рамках глобальных долгопериодичных ритмов, лежат колебания в соотношении площади поверхности морей Мирового океана и суши. При трансгрессиях уровня мирового океана, сопровождавшихся значительным обводнением континентов, доминировали влажные климатические интервалы, при регрессиях, сопровождавшихся похолоданиями и приростом суши за счет формирования значительного по площади ледового покрова арктических (и отчасти внутренних) морей, напротив - сухие. Эти процессы достаточно отчетливо фиксируются в чередовании ландшафтных смен позднего неоплейстоцена и голоцена в Якутии и других территориях. Увлажненность климата и сегодня оказывает значительное влияние на природные процессы в Якутии. $\mathrm{B}$ качестве примера можно привести реакцию горных ледников Якутии на современное потепление. Так, ледники хр. Сунтар Ха- ята (Южное Верхоятье), входящие в область влияния влагонесущих воздушных масс с Тихого океана при близких параметрах абсолютных высотных отметок с ледниками хребтов системы Черского, занимающими внутриконтинентальное положение (в зоне высокой континентальности климата), имеют вдвое большие площади. Значительное иссушение климата Якутии, по сравнению с настоящим временем, было установлено для XIX в. - времени завершающей фазы похолодания Малого ледникового периода, когда ледовитость арктических морей была максимальной. Сухой климат этого периода не мог, как и в случае с внутриконтинентальными хребтами системы Черского, сдерживать активное таяние льдов при переходе от похолодания к потеплению. В современных условиях, при значительном сокращении площадей морского и наземного ледового покрова и росте общей увлажненности климата, процесс таяния льда, как 
и в случае с ледниками Сунтар-Хаята, должен снизить свою динамику, а в отдельных случаях, вероятно, возможен даже прирост баланса массы отдельных ледников. Судя по динамике климата в XX в. основные волны (аномалии) потеплений и похолоданий в Якутии хорошо согласуются с динамикой глобальной атмосферы. Первая волна потепления, получившая название «Потепление Арктики 1930-х гг.», развивалась при усилении динамики западного переноса, вторая - от 1970-х гг. и по настоящее время развивается под влиянием циркуляции меридионального типа. При этом известное похолодание 1950-1960-х гг. проявилось в период общего ослабления циркуляции атмосферы при переходе одного ее типа в другой. Как и по ходу в 11-летних циклах, СА аномалии климата в рамках векового цикла тяготели к экстремумам этого цикла - максимуму и минимумам. Ранее подобное явление применительно к 11-летнему циклу было описано А.Л. Чижевским [15].

При оценке отклика криолитозоны на потепление климата и разработки геокриологических и общегеографических прогнозов необходимо учитывать большую инерционность географической оболочки и прежде всего морских и наземных льдов к процессу потепления. Так, таяние ледового покрова Северного Ледовитого океана, несмотря на активное потепление климата, начавшееся в середине 1970-х гг., до начала текущего столетия было незначительно. Однако в 2007 г., спустя более 30 лет от начала потепления, океан одномоментно потерял $25 \%$ своего ледового покрова. Последнее необходимо учитывать при разработках геокриологических прогнозов для Арктики и Субарктики, дабы снизить риски и избежать угрозы неожиданных и опасных природных катастроф.

Чего же следует ожидать в будущем?

Теплая и сухая фаза климата, развернувшаяся на равнинах Якутии в начале текущего столетия, продолжится в будущем еще как минимум на два-три десятилетия. Сильные засухи, подобные засухам 1920-х гг., вызвавшим голодомор и совпавшим с пандемией «испанки» и других инфекционных заболеваний (брюшной тиф, оспа, холера и др.), могут сохранить усиленную динамику в самое ближайшее время (2021-2025 гг.), а также в 2040-е и 2070-е гг. Об этом свидетельствуют как развивающаяся современная глубокая теплая климатическая аномалия, так и вся климатическая структура предыдущего векового цикла. В настоящее время мы находимся в начале второй волны 11-летнего цикла по ходу нового векового зародившегося 12 лет назад (2009 г.). Сотню лет назад в мире развернулась пандемия «испанки», возможно, вернувшейся к нам сегодня в обличии «COVID-19». В ту пору в Якутии горели леса, усиливали динамику опасные криогенные процессы, трансформировался режим наледей, половодий и паводковых волн, сейсмических проявлений и др. Развитие текущей теплой фазы климата также будет модулировать в самое ближайшие время активизацию широкомасштабных лесных пожаров и опасных криогенных явлений и процессов, связанных с вытаиванием пластовых и жильных льдов, площадным распространением термокарста, усиления динамики надмерзлотных подземных вод, солифлюкции, суффозии, процессов подтопления и заболачивания и др. Кроме того, можно ожидать всплеска опасных гидрологических, гидрогеологических и сейсмо-тектонических проявлений, особенно в периоды, близкие к переломам по ходу 11-летних солнечных циклов.

\section{Заключение}

Результаты анализа солнечно-тропосферных связей на уровне моделей линейных трендов и цикличности нестационарных процессов в многолетних рядах метеонаблюдений станции Якутск (среднегодовая температура приземного воздуха и атмосферные осадки) в графическом сопоставлении с ходами чисел Вольфа показали единство тенденций в активности Солнца и динамике рядов метеорологических элементов. В качестве важной закономерности следует отметить нелинейность гармонических колебаний на Солнце и в атмосфере. Выявлено устойчивое запаздывание по фазе на 1/4 периода - температуры и 1/2-осадков, относительно аномалий 11-летнего цикла СА (максимумов и минимумов). Причина этого явления представляется в инерционности отклика присущей всем геосферам географической оболочки на воздействие внешних энергетических импульсов. Не менее интересна выявленная внутривековая изменчивость тепло- и влагообеспеченности климата. Она проявляется в том, что пики температуры, опережая пики увлажненности на $1 / 4$ ритмической волны, создают условия для чередования периодов холодного и сухого, теплого и сухого, холодного и влажного, теплого и влажного климата. Согласно выявленным гелиогеофизическим предпосылкам, силь- 
ные засухи следует ожидать в первой половине - середине 2020-х гг. (2021-2025), а также в 2040-е и начале 2070-х гг. Они будут чередоваться либо совпадать (на отдельных участках) с сезонами, отличающимися ливневым характером атмосферных осадков. Эти явления будет модулировать периодичность широкомасштабных лесных пожаров и усиление динамики всего спектра опасных экзогенных геологических процессов. Во временных диапазонах, близких к минимумам и максимумам 11-летнего цикла, следует ожидать усиление рисков гидрологических, гидрогеологических и сейсмо-тектонических проявлений. Если обсуждать тенденции глобальных климатических изменений, то на сегодня нет оснований ожидать перехода к глобальному похолоданию. Это следует из многовекового режима солнечной активности, определяющей режим атмосферной циркуляции планеты. При этом периодические возвраты холодов возможны в периоды ослабления циркуляции атмосферы при переходах от одного типа циркуляции к другому, а также на волнах стоковых течений холодного воздуха из приполярных широт.

\section{Список литературы / References}

1. Шац М.М., Скачков Ю.Б. Климат севера: потепление или похолодание? // Климат и природа. 2016. № 2 (19) C. 27-37.

Shats M.M., Skachov Yu.B. Climate of the nortn: warming or cooling // Klimat i priroda. 2016. № 2 (19). P. $27-37$ (in Russian).

2. Дьяков А.В. Предвидение погоды на длительные сроки на энергоклиматической основе. Иркутск: Полимакс, 1953/2011. 157 c.

Dyakov A.V. Forecasting the weather for a long time on an energy-climatological basis. Irkutsk: Polimax, 1953/ 2011. 157 p. (in Russian).

3. Эйгенсон М.С. Солнце, погода и климат. Л.: Гидрометеоиздат, 1963. $273 \mathrm{c}$

Eigenson M.S. The sun, the weather and climate (L.: Gidrometeoizdat, 1963. 273 p. (in Russian).

4. Слепцов-Шевлевич Б.А. Геофизические основы морских гидрологических прогнозов. М., 1991, 109 с.

Sleptsov-Shevlevich B.A. Geophysical Foundations of Marine Hydrological Forecasts. M., 1991. 109 p. (in Russian).

5. Поморцев О.А., Кашкаров Е.П., Ловелиус Н.В. Биоклиматическая хронология голоцена: реконструкция и прогноз // Вестник Северо-Восточного федерального университета им. М.К. Аммосова. 2015. № 3 (47). С. 100-115.
Pomortsev O.A. Kashkarov E.P., Lovelius N.V. Bioclimatic chronology of the Holocene: reconstruction and forecast // Vestnik Severo-Vostochnogo federal'nogo universiteta im. M.K. Ammosova. 2015. № 3 (47). P. 100-115 (in Russian)

6. Perez Peraza J., Dorman L., Libin I. Space Sources of the Earth's Climate. Padova: Euromedia, 2011. 368 p.

7. Либин И.Я., Перес Пераса Х., Янке В.Г., Дорман Л.И., Трейгер Е.М. Гелиоклиматология: внеземные источники земного климата // Успехи современного естествознания. 2012. № 7. С. 67-70.

Libin I.Ya., Perez Perasa Kh., Yanke V.G., Dorman L.I., Treiger E.M. Helioclimatology: Extraterrestrial Sources of the Earth's Climate // Uspekhi sovremennogo yestestvoznaniya. 2012. No. 7. P. $67-70$ (in Russian)

8. Авакян С.В. Роль активности Солнца в глобальном потеплении // Вестник Российской Академии наук. 2013. T. 83. № 5. C. 425-436.

Avakyan S.V. The role of solar activity in global warming // Vestnik Rossiyskoy Akademii nauk. 2013. T. 83. № 5. P. 425436 (in Russian).

9. Trofimtsev Y.I., Pomortsev O.A., Popov V.F., Pomortseva A.A. Numerical modeling of harmonics in meteorological time series. AIP Conference Proceedings, 2017. P. 030025.

10. Pomortseva A.A., Pomortsev O.A., Popov V.F., Trofimtsev Y.I. TheInfluence of Solar Activity Rhythms on Precipitation Cycles during Climate Change in Central Yakutia International science and technology conference «Earth science» IOP Conf. Series: Earth and Environmental Science, 2021. P. 012018

11. Pomortsev O.A., Pomortseva A.A., Trofimtsev Y.I. Cyclic Organization of Geological Environment: Permafrost Zone of Yakutia International science and technology conference «Earth science» IOP Conf. Series: Earth and Environmental Science., 2019. P. 022059.

12. Жеребцов Г.А., Коваленко В.А., Молодых С.И., Кириченко К.Е. Влияние солнечной активности на температуру тропосферы и поверхноти океана // Известия Иркутского государственного университета. Серия «Науки о Земле». 2013. T. 6. № 1. C. 61-79.

Zherebtsov G.A., Kovalenko V.A., Molodykh S.I., Kirichenko K.E. Influence of solar activity on the temperature of the troposphere and ocean surface // Izvestiya Irkutskogo gosudarstvennogo universiteta. Seriya «Nauki o Zemle». 2013. Vol. 6. № 1. P. 61-79 (in Russian).

13. Жеребцов Г.А. Основные физические процессы в атмосфере Земли, криосфере и океане, определяющие особенности климатических изменений в XX в. и их связь с солнечной активностью // Солнечно-земная физика. 2011. Вып. 18. C. 40-50.

Zherebtsov G.A. The main physical processes in the Earth's atmosphere, cryosphere and ocean that determine the features of climate change in the twentieth century and their connection with solar activity // Solnechno-zemnaya fizika. 2011. Vyp. 18. P. 40-50 (in Russian).

14. Максимов Е.В. Ритмы на Земле и в Космосе. Тюмень: Мандер и Ка. 2005. 312 с.

Maksimov E.V. Rhythms on Earth and in space. Tyumen': Mander i Ka. 2005. 312 p. (in Russian).

15. Чижевский А.Л. Земное эхо солнечных бурь. М., $1976,366 \mathrm{c}$

Chizhevsky A.L. Earthly echo of Solar storms. M., 1976. 366 p. (in Russian). 